or the importance of the part injured, are usually of the gravest character. In cases of shock from mental emotion, if the result be not immediately fatal, the recovery from the severer symptoms is usually, though not always, rapid. There has been an antagonism of the nerve-force, which possibly may be recovered from before interchange of nerve-force has resulted in positive physical or chemical change, or, at least, before such physical or chemical change has rendered a return of nerve-force impossible.

In the severest forms of shock, from causes which act chiefly on the corporeal organisation, the injury is of the most serious, and often of a fatal character; and the shock, whether the injury be necessarily fatal or not, not unfrequently terminates in death. In such cases, several of the symptoms already described as occurring in the severer forms of shock are greatly aggravated. Coldness, pallor, immobility, and insensibility, are extreme. The pulse and respiration are scarcely, if at all, perceptible. The excito-motor functions are gravely impaired. The lids do not close when the conjunctiva is irritated. Deglutition is not possible to fluids or solids placed within the grasp of the constrictors. The sphincters are completely relaxed, and the urine is retained. Under such circumstances, especially when the fifth and glosso-pharyngeal nerves fail to excite any response in the nerve-centres, the gravest fears may be entertained that respiration itself will momentarily cease.

[To be continued.]

\section{CLINICAL STUDIES OF CANCER.}

BY CHARLES H. MOORE, F.R.C.S., Surgeon to the Middlesex and to St. Luke's Hospitals.

Treatment of Primary Tumours: Acetrc Acid. If there be one subject in surgical practice rather than another which claims revision, it is the want of effectual treatment of primary Cancers. To a large extent, the failure of surgery in respect to them is due to our deficient acquaintance with the disease; but it is also in part a consequence of the misapplication of knowledge actually possessed by the profession. Any practitioner who sees much of Cancer is not seldom first consulted when the possibility of removing the primary tumour is almost or quite gone by. Either measures have been previously adopted which were inadequate for the extinction of the disease, or throughout a long period of pretended treatment the propriety of an operation has not even been suggested to the patient, or the plan of forbearing to remove the tumour has been deliberately preferred. In some few persons, no doubt reasons which are usually held to be valid against any operation have rightly prevailed, but too often the aversion of the practitioner from an operation in Cancer has been the cause of the abandonment of the disease to its inevitable issue.

There is reason for such revision. Widely as knowledge on the subject of tumours has of late been diffused, and especially since the publication of $\mathrm{Mr}$. Paget's Lectures on Surgical Pathology, there is, however much, even yet too litble, fruit from it ; for there are still practitioners, though they are doubtless few, whose deliberate, but mistaken, views respecting Cancer throw on others the well-nigh hopeless task of retrieving their neglect, or the duty of watching without hope its lamentable consequences. The accumulation of abandoned cases in such an asylum as the Cancer Department of the Middlesex Hospital is distressing. Yet, even in the late stages at which such cases are brought to consultation, it sometimes happens that an operation is still possible, and the patient is relieved for a long time from the external ailment, or exchanges it for a later recurrence in a less painful and loathsome form ; but these satisfactory redemptions are few.

With what object are the operations in question avoided or delayed? Is it out of compliance with the antiquated error of the constitution being diseased rather than the part? As long ago as Denman, that theory has been denied; but, supposing it were even true, yet there is no delicacy of general health which should preclude the operation in these patients, or interfere with their prolonged comfort and usefulness after it. The contrary fact is occasionally shown by their ready recovery from the far more extensive operations which become necessary when the tumour has been suffered to enlarge. Is it from an apprehension of fatal accidents during the operation or the convalescence? This risk is pretty well known; it does not exceed ten per cent., and in the practice of many surgeons who are careful to select their cases on the general principles of surgery is not,.or is not more than;"half so great. Is it the fear of a local recurrence of the disease, and of consequent discredit for having advised the operation? Professional men, who advise prudently and frankly according to their expectations in the case, act aright in spite of discredit. And as to recurrence, an early operation is less likely to be so followed than a late one; whilst an operation, adequate in extent without being reckless, is indispensable for any success. Without the intention to extirpate this disease thoroughly, it would indeed be well not to interfere at all. Is it the persuasion that as a mortal disease it may as well be let alone? Such a conclusion may have been arrived at in days when there was no alleviation of pain by chloroform; but now the patients are entitled to profit by the knowledge we possess, that life is on the whole prolonged, and suffering mitigated by the removal of the primary tamour. Be it ever so true that Cancer sooner or later returns, that constitutes no ground for refusing to a patient the months or years of absolute health which an operation confers. To promise final exemption from the disease upon the removal of the first tumour would, in the present state of our knowledge, be unprofessional; it is no less so, in default of such a promise, to withhold from the patient the opportunity of temporary, and it may be long, respite by means of an operation. Is it, once more, to keep the patient in ignorance as long as possible of the nature and probable issue of her disease? By such a course, indeed, much present anxiety of mind is spared, except sometimes to the sufferer in secret; but it is at the expense of length of life and eventual increase of pain. From the expressions of patients who, aware too late of the nature of their ailment, cast much blame on their early advisers, it seems that, even at this day, some are suffered to live on in a delusive doubt as to their tumour "becoming Cancer", that is, in their sense, ulcerating, during all the time when the occult Cancer already existing is capable of being removed.

I am far from designing to fix on surgical practice in general, the fault of the progress of Cancer. Ignorance or timidity on the part of the patients them- 
[Fieb. 9, 1867.

selves, is the chief source of one deplorable and by the best practitioners Cancer is an all but unmastered complaint. If a difficulty in the diagnosis occasion delay in the removal of a cancerous tumour, the mischief which ensues is excusable. And, where an operation is refused by the deliberate judgment of the patient, or, for some acquired delicacy of the frame as a whole or disease of an internal organ, is held to be improper, all responsibility as to the consequences falls off from the medical attendant. Still there are cases in which the primary disease is allowed to make head, notwithstanding the glowing health which the patient, in common with most persons liable to Cancer, retains.

It may, I fear, be a thankless task to bring to light some of the consequences of error respecting Cancer with which I have become acquainted; but I am impelled to do so by the distressing nature of the cases which not unfrequently come to light. I ath persuaded also that the vast majority of the profession, whose competence to treat this disease makes them judges, not subjects, of my remarks, will appreciate an attempt to make such treatment as their own universal.

There is one question, before all others, relating to the treatment of primary Cancers, which presses for attention, and which I therefore allude to in the present communication: it is the injection of such tumours with acetic acid. It is not jet possible to foresee the extension of which that method of treating Cancer is capable. I have myself much hope from the employment of it; but I am already satisfied by its effects in secondary tumours, that it is not yet made applicable to the primary. From the first promulga. tion of this treatment by Dr. Broadbent, I have never used it or advised it in any case for which the ordinary operation was adapted, as it did not appear right to essay a remedy so little tried, and the adequacy of which for relieving all conditions of the disease was uncertain, in any person entitled to treatment known to be effectual. Already I have come to know that both disappointment and damage have resulted from an experimental use of the acetic acid in cases of primary Cancer of the breast, which Were fitted for removal by the knife. It is the more incumbent on me to say this, as by announcing the destruction of cancerous matter in the interior of a lymphatic gland with this acid, and the absolute dispersion of small recurrent subcutaneous cancerous tumours by the same means, I may unwittingly have encouraged others to what I cannot but think a misapplication of the remedy. So ready a method of disposing of Cancer is not yet won. Its unseen diffusion beyond the apparent limits of a tumour, is too certain a fact to justify confidence in injections for the removal of it. Neither is it to be yet expected of a remedy so slow in its action, and the management of which is far from perfected, that it should all at once supersede the more sure operation. The condition of primary tumours appears to me to make them particularly unfit for this treatment, for whilst they are growing, and may be large, the acid can only be thrown into them in small quantities, and at intervals. If used in a large quantity, it produces suppuration or sloughing, a disastrous action of a remedy in a primary Cancer; and in any quantity it produces swelling, with consequent uncertainty as to the area over which the effect of the acid has been secured, and delay in pursuing the treatment. Meanwhile the tumours continue to grow in the parts concealed by the swelling. I cannot think this to be right treatment of a primary Cancer.

Such objections may appear to relate no less to a secondary, recurrent, or advanced, than to a primary tumour; but the circumstances are in fact very dif- ferent. The treatment of the later disease is avowedly undertaken with less prospect of advantage than that of the primary. In those adranced cases the acid can achieve the reduction always, and sometimes the removal of the morbid mass; and it is only in such cases, where established methods of treatment are unsatisfactory, that those which make greater promise ought to be proved.

\section{a Case OF \\ MELANCHOLIA, ASSOCIATED WITH, AND PERHAPS DUE TO, ADDISON'S DISEASE.}

\author{
Br S. W. D. W I I I I A M S, M.D. \\ Assistant Medical Officer, Sussex County Asylum, \\ Hayward's Heath.
}

P. H., aged 46, was admitted into the Asylum at Hayward's Heath, on April 10th, 1866, in a state of acute melancholia, with delusions of a religious nature. Her chief delusion appeared to be that she was a devil in hell, and that she was being consumed by fire. Her distress was most acute, and she did nothing all day but sit and wring her hands, and cry and moan and bewail her lost fallen condition. Her general health was evidently indifferent. She looked pale and thin and yellow; the heart's action was feeble, but the sounds normal ; respiration was regular, and the lungs were apparently free from disease. She was small both in frame and in stature; very cachectic in appearance, and of a bilious temperament.

As regards her history, all the facts that could be gathered from her friends were, that she was the wife of a labourer, and had always been of a very active, anxious disposition; that for some months she had been gradually losing flesh, and had become more yellow; that for some weeks she had declared to her husband she was going out of her mind, but that she seemed perfectly sane up to a week before admission, when she suddenly became very restless and excited, passed a night without any sleep, and the next morning was both violent and deluded, so violent, indeed, as to require three men to restrain her.

On admission, she was ordered a pint of essence of beef-tea, a glass of port wine in the night, and a drachm of Taylor's liquor opii at bedtime, and a second dose at twelve o clock, if necessary.

April 12th. She was very incoherent and excited; slept several hours last night; she had to be forced with her food; she was ordered to have beef-tea and eggs, and to continue the liquor opii every four hours.

April 13th. She was quieter to day, and only required a dose of medicine at bedtime.

April 14th. She was ordered to have the Roman bath, and to take out-door exercise for an hour.

June 12th. She was somewhat better physically, and able to work a little in the laundry; mentally she had gradually lapsed into a state of chronic melancholy, and even when at work scarcely ever ceased silently weeping; all excitement had passed away. The following mixture was ordered to be taken in doses of an ounce, three times a day :-

Bo Liquoris morphiæ acetatis, ziv; ætheris chlorici, $\zeta_{i}$; acidi hydrocyanici diluti, $\xi_{i}$. Aquæ ad $\xi x i i$. July 24th. She was worse both mentally and physically; indeed, she was becoming a most miserable object; she was nothing but skin and bone. She 